\title{
Demanda turística por destinos com severas limitações de acesso: casos brasileiros
}

\author{
Glauber E.O. Santos*, André R. C. Perinotto** \\ Instituto Federal de São Paulo (Brasil) | Universidade Federal do Piauí (Brasil)
}

\author{
Carlos E. Silveira***, Juliana Medaglia***** \\ Universidade Federal do Paraná (Brasil) | Universidade Federal dos Vales do Jequitinhonha \\ e Mucuri (Brasil)
}

\author{
Heros A. S. Lobo*****, Maria H. S. G. G. Minasse $* * * * * *$ \\ Universidade Federal do Paraná (Brasil) | Universidade Anhembi Morumbi (Brasil)
}

\author{
Luiz E. P. Travassos********* \\ Pontíficia Universidade Católica de Minas Gerais (Brasil)
}

\begin{abstract}
Resumo: Uma das principais estratégias do Ministério do Turismo no Brasil para a ampliação do fluxo turístico nos destinos nacionais foi a delimitação de 65 destinos indutores do turismo no país. Esta pesquisa teve como objetivo analisar a demanda turística de lazer nos destinos indutores que possuem severas limitações de acesso. Para tanto, foi realizada uma pesquisa de campo em 3 destinos selecionados: Diamantina (MG), Parnaíba (PI) e Lençóis (BA). Os resultados obtidos apontam para o predomínio de turistas de meia idade, em sua maioria do sexo masculino e com distribuição homogênea das faixas de renda. O estado de São Paulo foi o principal emissor de turistas para os três destinos. As conclusões destacam o questionamento ao papel indutor do turismo destes destinos e a opinião positiva dos entrevistados em relação à dificuldade de acesso, apesar das grandes distâncias percorridas (média de $1.333 \mathrm{Km}$ ) e do uso significativo do modal terrestre para a viagem.
\end{abstract}

Palavras-chave: Demanda turística; Destinos indutores; Destinos remotos; Gestão de destinos turísticos.

\section{Tourism demand for destinations with severe access limitations: Brazilian cases}

Abstract: One of the main strategies of the Brazilian Tourism Ministry to increase tourist flows at national destinations was the nomination of 65 key destinations for tourism in the country. This research aimed to analyze the leisure tourism demand for key destinations with severe access limitations. A survey was conducted with tourists of 3 selected key destinations: Diamantina (MG), Parnaíba (PI) and Lençóis (BA). The main findings indicate the predominance of tourists of middle age, males and varied income levels. São Paulo is the single most important market for all 3 destinations. Among the main conclusions are the questioning of the key role of these destinations for tourism, and the positive opinion of tourists about access conditions, despite the large distances travelled (average of $1,333 \mathrm{Km}$ ) and the fact that a significant share of them used mainly inland modes of transport.

Keywords: Tourism demand; Remote destinations; Tourism destination management.

\footnotetext{
Mestre e doutor em Economia do Turismo e do Meio Ambiente; E-mail: glaubereduardo@gmail.com

** Doutor em Ciências da Comunicação; E-mail: perinotto@ufpi.edu.br

*** Doutor em Gestão e Desenvolvimento Turístico Sustentável; E-mail: caesilveira@gmail.com

**** Mestre em Comunicação e Turismo; E-mail: julianamedaglia@hotmail.com

***** Doutor em Geociências e Meio Ambiente; E-mail: heroslobo@ufscar.br

****** Bacharel em Turismo e Doutora em História; E-mail: mariegimenes@gmail.com

******** Doutor em Geografia; E-mail: luizepanisset@gmail.com
} 


\section{Introdução}

A atividade turística é um fenômeno de escala mundial que vem ganhando destaque no Brasil desde o século passado, sendo objeto de políticas públicas que visam o seu desenvolvimento de maneira sustentável. No plano da organização e gestão do turismo em âmbito nacional, a criação da EMBRATUR (então Empresa Brasileira de Turismo) no final da década de 1960, a alteração da personalidade jurídica da EMBRATUR em 1991 (convertida em Instituto Brasileiro de Turismo, com a assimilação de novas funções) e a criação do Ministério do Turismo (MTUR) em 2003 (com nova alteração das atribuições da EMBRATUR) são marcos institucionais em destaque.

Sob os auspícios do Ministério do Turismo as iniciativas voltadas para o planejamento, desenvolvimento e organização da atividade turística brasileira foram intensificadas. A partir do Plano Nacional de Turismo 2003-2007 (MTUR, 2003) foi criado o Programa de Regionalização do Turismo - Roteiros do Brasil (MTUR, 2013), em desenvolvimento até o presente. Posteriormente, no Plano Nacional de Turismo 2007-2010, foram definidos os 65 Destinos Indutores do Turismo no Brasil. Este Programa possui notória relevância, na medida em que objetiva irradiar regionalmente o turismo a partir de destinos com notória capacidade de atrair demanda turística e cuja oferta já tenha padrão internacional, ou apresente potencial para ter (Brasil, 2013).

Tradicionalmente, os estudos que originam políticas de turismo baseiam-se nas características da oferta, como ocorreu neste caso dos Destinos Indutores e em situações anteriores no Brasil (e.g., o Programa Nacional de Municipalização do Turismo). Contudo, não há como considerar o desenvolvimento turístico sem levar em conta a demanda, e sua capacidade de usufruir do destino ou produto oferecido (Santos e Kadota, 2012).

Embora o Programa 65 Destinos Indutores do Turismo no Brasil avalie e especifique a capacidade da oferta, verifica-se que muitos desses destinos não apresentam estrutura adequada para receber um fluxo representativo de turistas, especialmente no que diz respeito ao acesso da demanda. Muitos sequer conhecem, de forma sistemática, as características dos turistas que recebem e qual a relação entre suas motivações de viagem e os atrativos existentes no núcleo receptor, embora continuem recebendo turistas. Notadamente, tem-se o caso de alguns destinos que, apesar de oferecerem limitações de acesso, continuam recebendo turistas, o que gera o interesse em saber os fatores motivadores desta demanda e os elementos que determinam ou condicionam a opção por determinado destino.

A partir deste contexto, foi concebida e executada uma pesquisa que buscou analisar as motivações da demanda turística por destinos indutores do turismo localizados em áreas com severas limitações de acesso. $\mathrm{O}$ objetivo geral da pesquisa foi analisar a demanda turística de lazer por destinos brasileiros que ofertam atrativos turísticos de destacado potencial e cujo acesso não seja facilitado por voos regulares ou trajetos de curta distância em relação aos grandes polos emissores. A partir de um processo metodológico que será descrito posteriormente, os municípios de Diamantina (MG), Lençóis (BA) e Parnaíba (PI) foram selecionados dentre os 65 destinos indutores indicados pelo Ministério do Turismo. Estes destinos foram objeto de levantamentos documentais, bibliográficos e de pesquisa de campo de caráter quantitativo, cujos principais resultados são apresentados neste artigo.

\section{Referencial teórico}

A institucionalização das políticas públicas no Brasil aconteceu em três períodos principais, segundo Araújo e Taschner (2012): o primeiro deles da década de 1930 até a edição do Decreto Lei n.55, em 1966; o segundo até a reestruturação da EMBRATUR pela lei 8181/1991; e o terceiro até os dias atuais. Seria possível propor a divisão desse último período a partir da criação do Ministério do Turismo e da elaboração dos Planos Nacionais de Turismo desde então. Em termos de marco fundamental nas políticas nacionais de turismo, há um consenso entre diversos autores (e.g. Cruz, 2000; Beni, 2006; Araújo e Taschner, 2012) acerca da importância da criação da EMBRATUR nos anos 1960. Mesmo que outras ações anteriores também tivessem influenciado a atividade no âmbito Federal, em termos estruturais, a EMBRATUR protagonizou o principal momento de tangibilização. Na prática, o órgão passou a ser a organização nacional de turismo e dispersava as diretrizes nacionais às Unidades de Federação por meio dos escritórios nos Centros de Atividades Delegadas (CADES) existentes em cada um dos órgãos estaduais de turismo. Ao mesmo tempo em que as diretrizes criadas no âmbito federal eram distribuídas pelos Estados, a fiscalização e o controle eram subordinados à EMBRATUR, o que significava que toda a oferta turística nacional era classificada e regulada por ela, conforme o Decreto Lei n. 55. Pode-se dizer 
que, em virtude disso, a organização detinha grande poder sobre a oferta nacional. Mas, para que esse poder fosse justificado, possuía também um nível de excelência bastante elevado.

Após os anos 1980, o Brasil ingressou em uma fase marcada pela volta da democracia e pelo fim do controle estatal mais rígido. Como consequência disso, pela lei 8181/1991 o registro e a classificação dos empreendimentos turísticos deixaram de ser compulsórios. Assim, a oferta deixou de ser controlada pela EMBRATUR, que passa de empresa a autarquia, tendo seu nome alterado para Instituto Brasileiro de Turismo, e que, apesar de ainda desempenhar um papel importante no assessoramento aos investidores, teve seu poder enfraquecido, tanto em termos políticos quanto em termos financeiros, conforme Beni (2006): a) políticos, pela perda do protagonismo em definir a legislação que classificava a oferta de hotéis, agências, transportadoras turísticas e até albergues e campings; e b) financeiros, porque todas essas classificações e registros eram pagos.

Entrou-se em um período de transição durante o qual registrou-se uma queda significativa no turismo no país, seja por falta de políticas ou de informação confiável, ou em um âmbito mais amplo, pela instabilidade econômica. A última grande participação da EMBRATUR na política pública nacional deu-se nos anos 1990. Neste período, diversos fatores levaram ao lançamento do Programa Nacional de Municipalização do Turismo - PNMT - no Brasil, dentre os quais se destacam: a) a situação política do Brasil; b) o pensamento turístico, direcionado ao fortalecimento das comunidades locais no processo de desenvolvimento turístico; c) as orientações da Organização Mundial de Turismo (OMT); e d) a consideração de que a menor célula político-administrativa costuma ser o município (Silveira et al., 2014). O programa teve grande repercussão nacional e foi um dos marcos em termos de políticas públicas no país, ficando entre os dez programas de maior sucesso e aceitação na opinião da OMT (Bezerra, 2003). Esse programa teve entusiastas, assim como foi alvo de severas críticas. Conforme Fratucci (2005), tal como ocorre em diversas áreas no Brasil, não ficou imune a influências da política partidária. Com a mudança de governo entre grupos predominantes da política de direita para os grupos de esquerda, em 2002, o Programa deixou de existir.

Já no século atual, um novo cenário se estabeleceu em 2003, com a criação do Ministério do Turismo (MTur). Apesar de não ser considerada uma nova fase das políticas nacionais de turismo, constituiu-se em um marco histórico do turismo no país, sem antecedentes de similar natureza (Araújo e Taschner, 2012). Houve, desde o início daquela década, uma intensificação na elaboração de políticas relacionadas ao Turismo, resultante da criação do MTur. Beni (2006) ressalta a nova transformação da EMBRATUR, que passou a ser responsável especificamente pela promoção do Brasil no exterior. A formalização das políticas públicas nacionais se deu pela nova Secretaria Nacional de Políticas de Turismo, vinculada diretamente ao MTur, pela elaboração dos Planos Nacionais de Turismo (PNT).

Na primeira versão do Plano (2003-2007) houve a organização das políticas por meio de macro programas. Destes, destaca-se o macro programa 4, que tratava da "estruturação e diversificação, da oferta turística". A este programa estava vinculado o programa de roteiros integrados, lançado como Rotas do Brasil, e que na versão seguinte do Plano (PNT 2007-2010) consolidou o principal macro programa, o da Regionalização. Essa edição do Plano Nacional do Turismo, definiu as diretrizes políticas do MTur, ampliando o Plano original e direcionando ações de inclusão e descentralização. Entre essas políticas, destaca-se a definição de 65 Destinos Indutores do Turismo no Brasil, incluído como meta do macro programa de Regionalização. Este programa selecionou "roteiros e regiões que apresentam condições de serem trabalhados para adquirirem um padrão de qualidade internacional de mercado" (:52 Brasil, 2007). Tais destinos seriam os primeiros a serem desenvolvidos, e a meta se ampliaria para 87 roteiros que perpassariam 116 regiões turísticas do Brasil, como resultado de estudos do MTur e do Plano Cores do Brasil - Marketing Turístico Nacional (Brasil, 2005). Tencionava-se, portanto, irradiar regionalmente o turismo a partir de destinos com notória capacidade de atrair demanda turística e cuja oferta já tivesse padrão internacional ou apresentasse potencial para ter (Brasil, 2007).

Com o lançamento da versão mais recente do PNT “2013-2016” (Brasil, 2013), os 65 destinos deixaram de ser chamados de indutores, mas seguem no programa de competitividade, a fim de que mantenham a série histórica das pesquisas. Contudo, após oito anos de programa, segundo o MTur (:12 Brasil, 2015a), foi observado por meio dos estudos do Índice de Competitividade do Turismo Nacional "que muitos desses destinos ainda não são capazes de atrair e distribuir significativo número de turistas para seu entorno e dinamizar a economia do território em que está inserido, como inicialmente era esperado". Os destinos indutores, portanto, ainda que sejam mantidos nos estudos, deixaram de balizar o desenvolvimento turístico. Nesse sentido, o MTur, baseado na reestruturação do próprio Programa de Regionalização do Turismo, implementou a nova "Categorização dos Municípios Turísticos", mais 
ampla e com cinco categorias de municípios. Neste contexto, os 3.345 municípios das atuais 303 regiões turísticas existentes foram divididos entre as classes "A", "B", "C", "D" e "E".

As novas classes propostas baseiam-se no agrupamento por meio da análise de clusters. Este tipo de técnica estatística multivariada objetiva agrupar elementos analisados por meio de suas similaridades, com base nas variáveis (características) analisadas (Brasil, 2015a). Ainda de acordo com o MTur, as variáveis analisadas foram orientadas pelos critérios de "Vínculo" (relação direta com a atividade turística); "Disponibilidade" (dados acessíveis ao MTur); "Comparabilidade"(dados que possibilitem a comparação objetiva entre os municípios do universo a ser estudado); "Abrangência" (dados disponíveis para o universo de estudo) e "Atualização" (possibilidade de atualização periódica dos dados). Todos os dados são baseados em fontes secundárias já presentes nas bases de dados do Ministério. Nessa nova metodologia, todos os três municípios alvo da pesquisa, que anteriormente compunham o rol de destinos indutores, foram agrupados na categoria "B" (Brasil, 2015b).

Ainda que seja possível perceber que estudos que originam políticas baseiem-se principalmente nas características da oferta, como ocorreu neste caso dos Destinos Indutores e em situações anteriores no Brasil, não há como considerar o desenvolvimento turístico sem levar em conta a demanda, e sua capacidade de usufruir do destino ou produto oferecido.

No caso desta nova categorização, as "variáveis selecionadas para a categorização dos municípios do Mapa do Turismo" (Brasil, 2015a) incluem o número de estabelecimentos formais cuja atividade principal é hospedagem e o número de empregos formais no setor de hospedagem, pelo lado da oferta, com dados obtidos por meio da Relação Anual de Informações Sociais (RAIS) do Ministério do Trabalho e Emprego. Pelo lado da demanda, foram utilizados a estimativa de turistas a partir do 'Estudo de Demanda Doméstica' e a Estimativa de turistas a partir do 'Estudo de Demanda Internacional', ambos frutos de parceria Fundação Instituto de Pesquisas Econômicas (FIPE/MTur).

A proposta busca ir ao encontro das necessidades do mercado, ainda que apresentada como um projeto piloto. Assim, na opinião dos autores deste artigo, corroboram a visão sistêmica proposta por Beni (2001), segundo quem as relações operacionais são consolidadas no ambiente do mercado turístico que, por sua vez, é calcado na oferta de bens e serviços a clientes reais ou potenciais que os demandem. O mercado, por sua vez, baseia-se em fatores como: as condições e o conhecimento do que deve ser produzido; a inexistência de destinações turísticas sem turistas; a dependência íntima entre oferta e a existência de uma demanda; a previsibilidade da demanda, a qual é fundamental para o planejamento de destinos. Neste cenário, a demanda turística deve estar adequada à oferta dos produtos dos destinos turísticos, e disso depende o sucesso de um determinado destino, tendo em mente, ainda, que a quantidade de demanda deve ser proporcional a quantidade da oferta (OMT, 2003).

No caso específico dos destinos pesquisados, outros elementos devem entrar na relação entre oferta e demanda, por se tratarem de destinos com notória atividade turística, mas que encontram-se alijados de mercados emissores tradicionais do Brasil. Partiu-se de pressupostos baseados, por exemplo, em estudos da área de geografia, como a teoria da "distance decay" que segundo Eldridge e Jones (1991 apud Mckercher e Lew, 2003), apregoa que a distância funciona como uma forma de atrito na demanda, fazendo com que quanto maior seja a distância entre origem e destino, menor seja a demanda por este. De acordo com McKercher e Lew (2003), a teoria teve tanta repercussão na geografia que passou a ser considerada uma de suas leis básicas, tendo sido usada em várias situações, inclusive no turismo, especialmente nas décadas de 1960 e 1970, antes da incorporação de técnicas mais avançadas de previsão de demanda que ocorreram nos anos seguintes.

Teorias desse tipo reforçam o ponto de vista de autores como Boullón (2002) que determina, já no turismo especificamente, "raios de influência" entre pontos de partida de viajantes e destinos, afirmando que há uma relação entre tempo de deslocamento confortável para determinado complexo turístico e a procura por esses locais. O autor menciona um limite de duas horas de transporte terrestre, e que esse tempo depende do modal utilizado e da topografia da região visitada.

Há que se ter em mente, todavia, que estas afirmações foram descritas na década de 1980, já que a primeira edição da obra mais famosa de Boullón data de 1985. Nesse ínterim muita evolução houve no conforto e até de entretenimento nos meios de transporte. Rodovias e ferrovias deixaram os deslocamentos mais estáveis e os próprios usuários mudaram com uma sociedade mais habituada a gastar tempo em deslocamentos. Contudo, as distâncias e o tempo de deslocamento seguem tendo um papel preponderante nas escolhas por destinações.

Com base em outra metodologia, Rabahy et al. (2008) afirmam que, segundo dados referentes ao turismo brasileiro e mundial, existe uma propensão de localidades mais próximas a grandes centros emissores receberem mais turistas que as mais distantes. Os autores descrevem um modelo matemático 
que relaciona as forças das massas (emissivo e receptivo) e uma proporcionalidade inversa para as distâncias. Assim, admitem que quanto maior a proximidade entre os destinos e os centros emissivos, maiores são suas probabilidades de êxito (Rabahy et al. 2008). Dessa forma, há como se considerar uma tendência a que destinos remotos (em termos espaciais) ou com acesso precário ou inapropriado (que aumente o tempo de deslocamento), apresentem peculiaridades em relação ao tipo de público visitante e suas motivações.

O caso apresentado neste artigo trata, justamente, de destinos cuja singularidade pode ser considerada suficiente para atrair turistas. As hierarquias de valoração de seus atrativos podem ser dispostas nas categorias mais altas, a ponto de terem sido enquadrados entre os 65 destinos mais competitivos no Brasil pela metodologia proposta pelo MTur/SEBRAE/FGV (Barbosa, 2014), mas que, em função de suas características, possuem limitações de acesso.

\section{Caracterização dos destinos pesquisados}

A pesquisa foi executada nos municípios de Diamantina (MG), Lençóis (BA) e Parnaíba (PI). A descrição destes três destinos se inicia com os aspectos que os aproximam e que serviram de justificativa para sua seleção para a aplicação da pesquisa. As três localidades foram inicialmente classificadas como destinos indutores pelo Ministério do Turismo (MTur) e atualmente classificadas como nível B pelos critérios do Índice de Competividade dos destinos. São também locais de difícil acesso, principalmente relacionais com os diferentes modais de transporte: enquanto Diamantina não é atendida por voos comerciais regulares, Lençóis é atendida de forma intermitente e Parnaíba passou a ser atendida no primeiro semestre de 2014, mas teve suas operações comerciais encerradas em novembro de 2015, sem previsão de retorno até o fechamentos deste artigo (dez./2015). A seguir serão apresentadas algumas características de cada um desses três destinos.

\subsection{Diamantina}

O município de Diamantina está situado no norte do Vale do Jequitinhonha, na Zona Central do estado de Minas Gerais e possui área territorial de $3.870 \mathrm{Km}^{2}$. A cidade está a $292 \mathrm{~km}$ da capital estadual, Belo Horizonte. Sua população totaliza 47.803 habitantes (IBGE, 2014). Na atualidade, os acessos terrestres estão limitados ao modal rodoviário, com ao menos oito frequências a Belo Horizonte por dia, e com duas linhas que ligam Diamantina a São Paulo, em serviços convencionais.

O Aeroporto Presidente Juscelino Kubistchek está localizado a aproximadamente $4 \mathrm{~km}$ do centro da cidade de Diamantina e é administrado pela Prefeitura Municipal. Possui um terminal de passageiros e saguão, salas de embarque e desembarque, banheiros, e tem capacidade para receber até sete mil passageiros por ano, além de ser adaptado para atender passageiros portadores de necessidades especiais. $\mathrm{O}$ aeroporto foi homologado pela Portaria de Homologação da ANAC n ${ }^{\circ}$ 1040/SIE, de 03 de julho de 2009. A empresa Trip Linhas Aéreas era a única a operar no aeroporto, até 2012. Nesse ano, com o início das negociações entre as empresas Trip e Azul - que culminaram na aquisição da primeira pela segunda - os voos passaram a sofrer alteração de rota e frequência, até serem descontinuados em 2013, permanecendo nessa situação até 2017 quando o Governo do Estado incluiu a cidade no projeto Voe Minas Gerais, e Diamantina voltou a receber voos durante a semana. A frequência dos voos ainda não é definitiva.

A existência de linhas de ônibus intermunicipais e interestaduais regulares que atendam ao destino e a existência de um terminal rodoviário com oferta de transportes para quem desembarca é também um aspecto positivo em relação ao transporte. Contudo, os serviços pouco adequados no terminal e a falta de um sistema regular de transporte turístico, além das dúvidas acerca do método de cobrança utilizado por taxistas, já que não são adotados taxímetros nesses veículos em Diamantina, estão entre os itens com avaliação negativa no destino.

O Turismo em Diamantina ganhou impulso com a declaração de Patrimônio Cultural da Humanidade pela Organização das Nações Unidas para a Educação, a Ciência e a Cultura (UNESCO) em 1999. O processo de inscrição e outorga no título mobilizou a cidade e ocasionou um aumento substancial na quantidade de turistas, fenômeno que segundo Marques (2009), foi percebido pela própria população diamantinense. Além disso, Diamantina está localizada em uma das pontas da Estrada Real, complexo turístico que fez com que o governo mineiro criasse o Instituto Estrada Real (IER) órgão que busca melhorar a atividade turística nos municípios que a compõe. Neste contexto, coexistem elementos históricos importantes na formação da oferta turística do destino Diamantina originados desde o isolamento provocado pela ação da Coroa Portuguesa na região - dada a pujança econômica oriunda da atividade 
garimpeira e até mesmo, os hábitos 'nobres' da elite, que incluíam música, teatro e afins. Também se fizeram presentes figuras históricas que ajudam a caracterizar a oferta turística e despertam curiosidade nos visitante, como a escrava Chica da Silva e Juscelino Kubitscheck de Oliveira, presidente do Brasil no período de 1956 a 1960 - personalidade política de grande importância e representatividade no país, cuja simpatia e musicalidade são atribuídas à sua terra natal (Lima e Maia, 2010).

\subsection{Lençóis}

O município de Lençóis localiza-se na Chapada Diamantina, uma região no interior do Estado da Bahia composta por 58 municípios (Misi e Silva, 1996). Destes, destacam-se na paisagem as escarpas sedimentares da Serra do Sincorá, distribuídas por 5 municípios: Lençóis, Palmeiras, Andaraí, Mucugê e Barra da Estiva (Pedreira, 2013). Em conjunto com Iraquara, estes municípios formam um dos principais núcleos receptores de turistas da região. Embora a Chapada Diamantina, e especialmente Lençóis, possuam atributos de elevado valor histórico e cultural - como o ciclo de exploração de diamantes, que trouxe pujança econômica para a região, com destaque para o período entre 1844 e 1871 (Pedreira, 2013) -, é a natureza peculiar da Chapada Diamantina que se constitui em seu principal atrativo turístico. Destacam-se as cachoeiras, morros, cânions, cavernas e trilhas, entre os muitos elementos que compõem a imagem do destino.

O acesso rodoviário para Lençóis é asfaltado, com uma distância de $426 \mathrm{~km}$ da capital do Estado, Salvador, e $1.069 \mathrm{~km}$ de Brasília-DF. O acesso ao município também pode ser feito por meio do aeroporto Horácio de Mattos, localizado a $22 \mathrm{~km}$ do centro da cidade e com pista pavimentada e terminal de embarque em boas condições de atendimento. O aeroporto foi inaugurado em junho de 1998, com um dos objetivos principais de fomentar o turismo na Chapada Diamantina. Desde 2009, passou a receber voos comerciais mais frequentes, iniciados pela companhia aérea Trip, em um trecho de aproximadamente 50 min. de duração partindo de Salvador. A regularidade dos voos variou muito desde então: voos diários em algumas épocas e na alta temporada e voos em apenas dois dias da semana em outros períodos.

Aárea total do município é de 1.277,03 km², com população atual (2015) estimada de 11.445 habitantes e confirmada pelo censo de 2010 de 10.368 habitantes. Destas, a população economicamente ativa de pessoas com mais de 10 anos é de 4.838 pessoas, com sensível desigualdade de sexos em favor do masculino (57\%). O setor de serviços é o principal da economia, respondendo por aproximadamente $66 \%$ do PIB municipal (IBGE, 2015). De acordo com a Prefeitura Municipal, o Turismo responde pela maior parte deste setor, sendo o principal segmento da economia Lençoense (Prefeitura Municipal de Lençóis, 2015).

\subsection{Parnaíba}

Parnaíba, município litorâneo do Estado do Piauí, possui população de aproximadamente 145.729 mil habitantes, o segundo município em termos de população no Estado, estando atrás somente da capital Teresina (IBGE, 2010). Parnaíba está distante mais de $340 \mathrm{~km}$ da capital, sendo ligada por rodovia com pista simples, porém pavimentada com manutenção anual.

Parnaíba é uma cidade considerada turística, principalmente pelo fato da existência do Delta do Parnaíba. Além disso, a cidade possui a praia da Pedra do Sal, ao mesmo tempo em que está próxima da cidade de Luís Correia, caracterizando um turismo focado em passeios ao Delta e no segmento de "Sol e Mar" (Pereira et al., 2011).

O município de Parnaíba perpetra componente da "Rota das Emoções" formada entre: Jericoacoara (CE), Lençóis Maranhenses (MA) e o Delta do Parnaíba (PI). Trata-se de um município historicamente e economicamente importante para o turismo do Piaú, e para a economia da região Norte do Estado.

$\mathrm{O}$ aeroporto da cidade recebeu investimentos federais para receber voos comerciais entre 2009 e 2012, com ampliação da pista de pouso e investimentos na parte das esteiras e estrutura para receber as empresas aéreas. Em 2014 a empresa Azul Linhas Aéreas iniciou voos comerciais entre os trechos por Parnaíba de Teresina/PI e Fortaleza/CE, porém os voos foram encerrados, sem renovação junto à ANAC, em novembro de 2015. Com isso, a região turística do Litoral do Piaú, voltou a ter apenas o modal rodoviário como principal meio de acesso, uma vez que também não existem portos náuticos na região.

Uma pesquisa da Fundação Centro de Pesquisas Econômicas e Sociais do Piauí (CERPRO, 2013) identificou uma característica dos visitantes do Litoral do Piauí, em Parnaíba, em relação aos turistas brasileiros: $78,0 \%$ são nordestinos, sendo $57,6 \%$ piauienses, $11,5 \%$ cearenses e $6,7 \%$ maranhenses. Tais dados evidenciam aspectos de distribuição, em que a proximidade é preponderante na visitação deste destino. 


\section{Materiais, métodos e etapas da pesquisa}

O objeto da pesquisa realizada foi a demanda turística por destinos brasileiros que ofertam atrativos turísticos de destacado potencial e que possuem severas limitações de acesso. Como ponto de partida para a seleção dos destinos estudados, adotou-se a lista de 65 destinos turísticos indutores definidos pelo Ministério do Turismo (Barbosa, 2014). A depuração dessa lista foi realizada em três etapas. Inicialmente, foram excluídos os 37 destinos que contam com aeroportos e voos regulares. Na sequência, foram excluídos os 25 destinos localizados a menos de $250 \mathrm{Km}$ de aeroportos com voos regulares. Por fim, optou-se por selecionar três destinos que oferecessem à pesquisa relativa diversidade de oferta e demanda turísticas, sem prejuízo às definições centrais colocadas pelo objetivo da pesquisa (fig. 1). Outro recorte realizado na amostra considerada foi em relação à distância de origem dos turistas. Para tanto, foram entrevistados apenas turistas de média ou longa distância, sendo esse conjunto definido como aquele composto por residentes em localidades situadas a pelo menos $400 \mathrm{Km}$ de cada destino pesquisado. Desta forma, as respectivas capitais dos estados de cada destino foram excluídas da amostra, assim como outros mercados emissores relevantes (fig. 1). O objetivo desse critério de seleção foi direcionar a pesquisa para aqueles turistas que enfrentam maiores dificuldades de acesso ao destino. Por fim, a amostra incluiu apenas turistas cujas viagens eram motivadas por lazer, sendo desconsiderados aqueles que viajavam por outros motivos, como negócios ou visita a amigos e parentes.

Figura 1: Localização dos destinos pesquisados

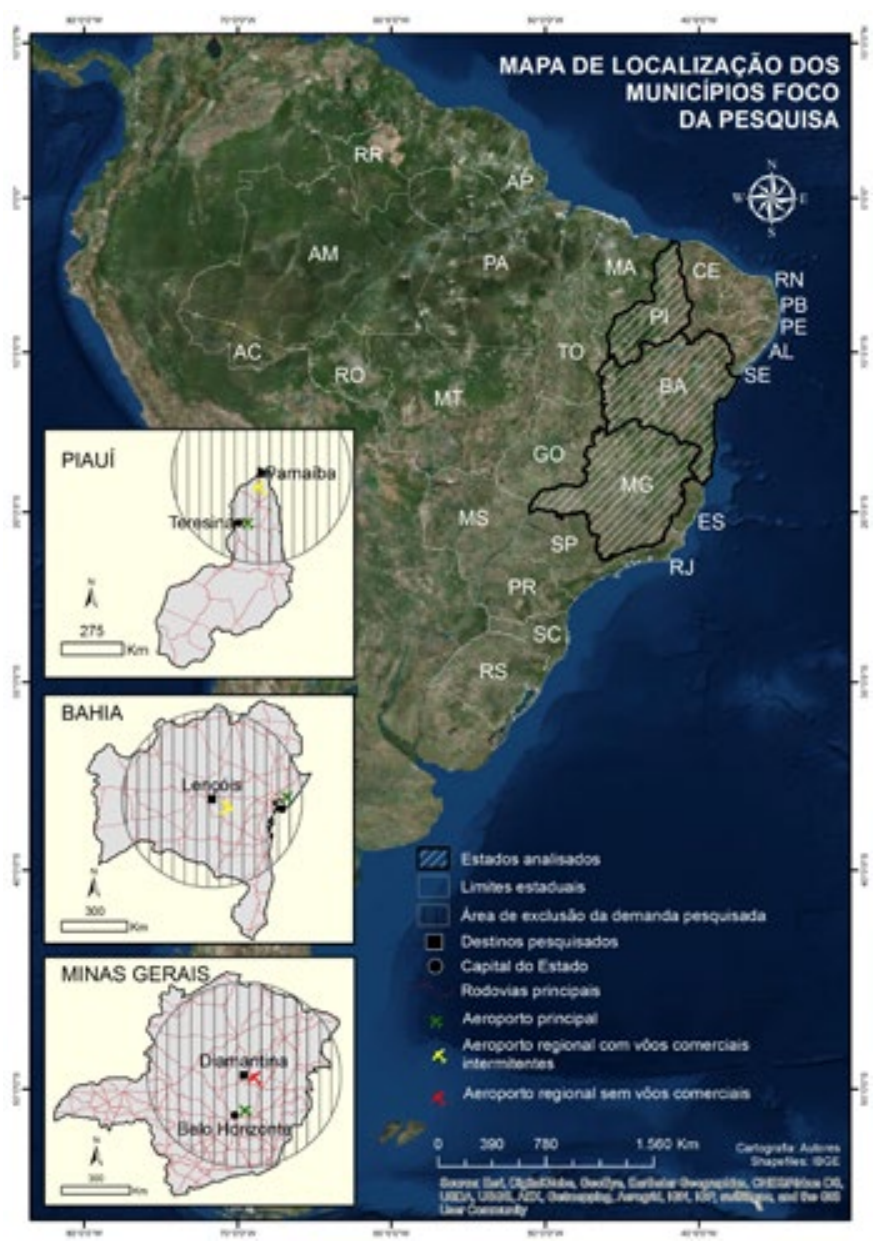


A realização dos trabalhos de campo tomou por base a pesquisa bibliográfica inicial, por meio da qual foram encontrados os subsídios para a elaboração de um questionário. Os enfoques deste instrumento de coleta de dados foram: a) a caracterização do perfil socioeconômico dos visitantes; e b) a obtenção de informações sobre sua motivação para a realização da viagem e satisfação com o destino visitado, bem como sobre os atrativos e serviços utilizados.

O pré-teste do questionário foi realizado em Diamantina, em maio de 2014, com um total de 9 aplicações durante um evento tradicional local denominado Café do Beco. Para esta ocasião, foram entrevistados turistas de qualquer origem, sem restrição de distância até o destino. Os dados coletados durante o pré-teste não foram considerados para os resultados da pesquisa, mas possibilitaram a realização de ajustes no questionário, em função de aspectos como: tempo de aplicação, compreensão das questões e sobreposição parcial dos conteúdos abordados. Estes ajustes levaram ao modelo final de questionário que foi aplicado nos 3 destinos pesquisados com o uso de plataformas digitais móveis (tablets). $\mathrm{O}$ registro das opiniões dos turistas era feito em campo e, na medida do possível, transmitido da própria plataforma de pesquisa via correio eletrônico, para duplicar o armazenamento dos dados coletados.

A coleta efetiva de dados em campo foi realizada nos meses de agosto e outubro de 2014 em Diamantina, julho e agosto de 2014 em Parnaíba e em Janeiro de 2015 em Lençóis. A seleção desses momentos de pesquisa buscou priorizar a alta temporada de cada local, a fim de viabilizar a obtenção de um maior número de observações. Assume-se que o direcionamento da amostra para os momentos de alta temporada turística não tenha influenciado substancialmente os resultados, já que os temas de interesse não devem apresentar variação sazonal relevante.

Os pesquisadores procuraram e abordaram turistas nos principais pontos de fluxo, incluindo atrativos e estabelecimentos de serviços turísticos. O processo amostral em cada dia de trabalho pode ser classificado como incidental, já que todos os potenciais entrevistados foram abordados. Os turistas foram entrevistados em qualquer fase de suas estadas no destino. Em média, 51\% do tempo de estada previsto no destino já havia transcorrido no momento da entrevista. Excursionistas no destino não foram entrevistados.

O levantamento de dados durou em média 11 dias em cada destino. Contudo, apesar dos esforços, um total de apenas 89 turistas foram entrevistados, sendo 38 em Diamantina, 34 em Lençóis e 17 em Parnaíba. O principal motivo para a obtenção do reduzido número de entrevistados foi o pequeno fluxo de turistas com as características de interesse nos destinos selecionados. Em média foram encontrados pouco menos de 3 turistas que faziam parte da população de interesse por dia em cada destino. A grande maioria dos turistas abordados residiam a menos de $400 \mathrm{Km}$ do destino ou não declararam estar viajando por motivo de lazer.

Os dados coletados foram compilados e sintetizados em planilhas, possibilitando uma visão mais abrangente da amostra. A análise realizada foi essencialmente descritiva, com apontamentos de suas características mais marcantes e eventuais discrepâncias e diferenças entre os destinos.

\section{Resultados do levantamento empírico e discussões}

A idade dos entrevistados teve média de 41,8 anos e desvio-padrão de 14,1 anos, indicando uma maior frequência de turistas de meia idade. Houve predominância de turistas do sexo masculino (65\%), especialmente em Parnaíba, onde a parcela de homens atingiu $77 \%$ dos entrevistados. O grau de escolaridade dos turistas pesquisados foi relativamente alto. A maioria dos entrevistados tinha ensino superior completo (56\%). Uma parcela não desprezível (14\%) tinha pós-graduação. 32\% dos entrevistados tinham renda familiar entre 2 e 5 salários mínimos, $30 \%$ de 5 a 10 salários e $32 \%$ acima de 10 salários. Portanto, pode-se dizer que o perfil dos turistas entrevistados foi bastante variado em relação à renda.

A maior parte dos entrevistados era de brasileiros. Apenas 11\% dos entrevistados residiam fora do país, oriundos de países como Alemanha, Argentina, Chile, França, Inglaterra, Israel e Itália. Em Diamantina, $37 \%$ dos entrevistados residiam dentro do próprio estado de Minas Gerais. Este foi o único destino para o qual o fluxo intraestadual se revelou importante. Ademais, apenas o estado de São Paulo se destacou como origem relevante de turistas para os destinos analisados, representando $30 \%$ do total de entrevistados.

Em média, os entrevistados se deslocaram $1.333 \mathrm{Km}$ entre seus locais de residência e os destinos visitados. Essa média foi inferior em Lençóis $(1.025 \mathrm{Km})$ e superior em Diamantina e Parnaíba (1.549 $\mathrm{Km}$ e $1.469 \mathrm{Km}$, respectivamente). Contudo, essa diferença não é estatisticamente significante ( $>0,1)$. O tempo mediano de deslocamento entre o local de residência e o destino foi de 9 horas. Parnaíba se destacou com um tempo mediano de deslocamento de 18 horas. Neste caso específico, a capital do Estado 
que é grande demandante para este destino, Teresina, está localizada a $340 \mathrm{~km}$, em trajeto rodoviário com duração de 6 horas, utilizando ônibus.

De maneira geral, apesar das largas distâncias percorridas, a opinião dos entrevistados com respeito ao transporte de acesso ao destino não foi negativa (fig. 2). Opiniões negativas foram reveladas por apenas $13 \%$ em relação às estradas, $16 \%$ em relação aos preços do transporte e $18 \%$ em relação ao tempo de deslocamento. Os resultados apontaram também que as opiniões sobre o transporte não têm relação com a distância percorrida entre a residência e o destino. Em outras palavras, turistas que fizeram deslocamentos maiores não têm opiniões significativamente mais positivas ou negativas sobre o transporte do que aqueles que percorreram trechos mais curtos.

Figura 2: Avaliações sobre diferentes aspectos do transporte

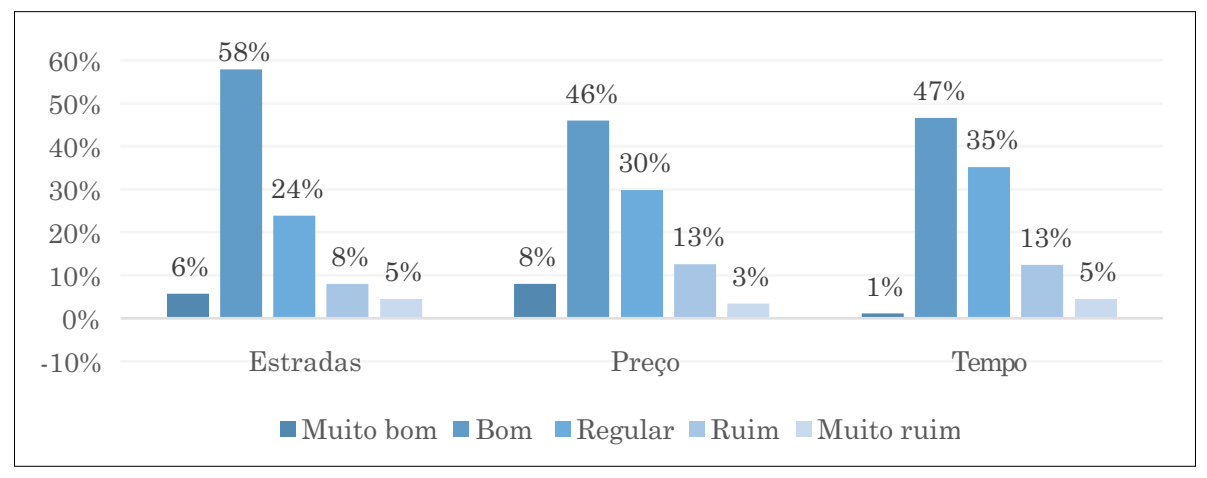

Dentre os entrevistados, somente 1\% indicou que os benefícios da visita ao destino apenas "talvez" tenham compensado o esforço de deslocamento, sendo que os $99 \%$ restantes afirmaram que a visita certamente compensou o deslocamento. Essa avaliação tem fundamento não apenas nos julgamentos positivos sobre as condições do deslocamento, mas também nas percepções positivas sobre o destino em si. $53 \%$ dos entrevistados julgaram como "muito bom" o destino visitado e $47 \%$ julgaram como "bom", sendo que nenhum turista pesquisado avaliou de forma regular ou negativa os destinos pesquisados.

A maioria dos indivíduos entrevistados (73\%) não visitou o destino em razão de um atrativo turístico especial. Contudo, uma parcela relevante (27\%) indicou ter se deslocado até o destino em busca de um atrativo em particular. É interessante notar que aqueles que viajaram motivados por um atrativo específico realizaram deslocamentos médios de $1.821 \mathrm{Km}$, enquanto os demais se deslocaram em média $1.144 \mathrm{Km}$ (fig. 3). A diferença entre esses dois valores é estatisticamente significante $(p<0,01)$. Portanto, pode-se afirmar que os fluxos turísticos de mais longa distância tendem a ser formados por parcelas maiores de indivíduos motivados por um atrativo específico. De outro lado, os fluxos originados em mercados mais próximos tendem a ser formados por indivíduos com interesses mais inespecíficos no destino.

Figura 3: Distância média entre origem e destino por motivação específica

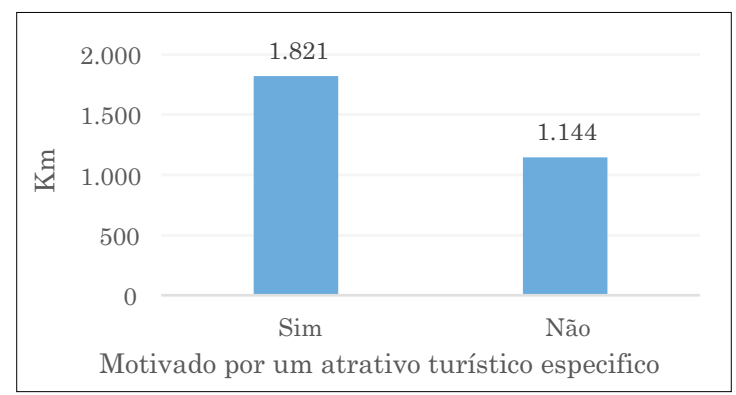


O automóvel particular foi utilizado por quase de dois terços (63\%) dos entrevistados para chegar aos destinos, tendo sido o transporte coletivo rodoviário utilizado pelos $37 \%$ restantes dos turistas pesquisados. A grande maioria dos entrevistados (88\%) não utilizou qualquer serviço de agências de turismo para visitar os destinos selecionados. Dois terços dos turistas pesquisados se hospedaram em hotéis, pousadas ou similares (66\%). Apesar da motivação principal de lazer das viagens pesquisadas, $21 \%$ dos entrevistados se hospedaram em casa de amigos ou parentes. Outros meios de hospedagem, como camping e imóveis alugados ou próprios, respondem pelos $13 \%$ restantes dos entrevistados.

Os três destinos selecionados se diferenciaram significativamente $(p<0,01)$ em termos de duração média das estadas dos turistas pesquisados. Enquanto em Diamantina a permanência média foi de 3,2 dias, em Lençóis este valor foi de 6,5 dias e em Parnaíba 11,5 dias (fig. 4). Não foi identificada relação significante em relação à distância entre a origem e o destino e o número de pernoites neste $(p>0,1)$. Turistas residentes em locais mais distantes apresentam permanências médias similares àqueles que residem em locais mais próximos ao destino, o que contradiz estudos anteriores (e.g. Santos et al., 2015).

Fig. 4. Permanência média dos turistas por destino

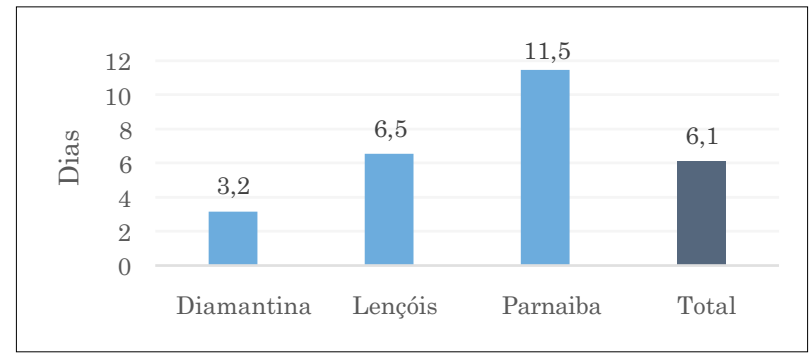

O gasto per capita diário médio dos turistas foi de $\mathrm{R} \$ 202,00$, sendo que este valor não apresentou variação significativa entre os três destinos selecionados $(p>0,1)$. Tampouco o gasto per capita diário médio indicou variação em função da distância entre origem e destino $(p>0,1)$.

Apesar do relativo isolamento dos destinos pesquisados, a maior parte das viagens observadas tem como único destino os locais pesquisados (69\%). Mesmo entre as viagens com mais de um destino, a localidade pesquisada constituía o principal destino da viagem para a maioria dos entrevistados. $62 \%$ dos turistas afirmaram que teriam visitado a localidade pesquisada mesmo se os demais destinos não fizessem parte da mesma viagem. Além disso, pouco mais da metade dos entrevistados não estava visitando o local pela primeira vez (53\%). O número de turistas visitando o destino pela quinta vez ou mais atingiu $20 \%$ do total de pesquisados. A incidência de viagens repetidas para o destino não se mostrou relacionada com a distância da origem $(p>0,1)$.

O grau de conhecimento prévio dos turistas pesquisados sobre o destino visitado era intermediário. $35 \%$ indicaram que conheciam muito sobre o destino antes da visita, 38\% disseram conhecer o destino mais ou menos e $27 \%$ indicaram conhecer pouco. O grau de conhecimento não apresentou relação significativa com a distância percorrida entre o local de residência e o destino $(p>0,1)$.

O meio mais utilizado para obter informações sobre os destinos visitados foi a Internet. $59 \%$ dos entrevistados utilizaram sites da web e $40 \%$ utilizaram informações de redes sociais da Internet. O grande uso da Internet para a pesquisa de informações pelos turistas encontra apoio teórico nas ideias de diferentes autores. Para Castells (2001), a internet é um moderno ambiente de comunicação, de alcance mútuo. Esta posição é complementada por Perinotto (2013), que defende a internet como uma peça constitucional que sustenta os projetos turísticos, em função do largo alcance que a internet propicia em termos de usuários.

As informações de amigos ou parentes foram utilizadas por $57 \%$ do total de entrevistados. Contudo, deve-se notar que as informações de amigos ou parentes, apesar de ligeiramente menos consultadas do que os sites da web, se destacaram pela intensidade do uso. 33\% dos entrevistados afirmaram ter utilizado "muitas" informações de amigos ou parentes, enquanto apenas $19 \%$ indicaram ter utilizado "muitas" informações de sites. A obtenção de menos informações em sites do que através 
de amigos ou parentes deve-se ao fato da confiabilidade e da intimidade com o informante. Maior confiabilidade é atribuída à informação de amigos ou parentes do que à informação obtida em outros meios de comunicação/informação. Guerra et al. (2014) destacam que os viajantes usam vários tipos e quantidades de fontes de informações turísticas para responder às suas necessidades de planejamento de viagens, tornando o processo mais dinâmico.

Meios de comunicação como guias turísticos, mídia impressa e televisão tiveram participações bastante pequenas no fornecimento de informações para as viagens pesquisadas. A Internet teve ainda grande importância para a realização de reservas de serviços, pois fora utilizada por quase metade (49\%) dos entrevistados para reservar serviços de hospedagem e por pouco mais um quinto (21\%) para reservar serviços de transporte. Essas evidências estão em acordo com as constatações de Portas e Fuesanta (2014), os quais afirmam que os processos de intermediação de compras para as viagens passam por mudanças cada vez mais nítidas, em função das facilidades que a internet apresenta para os consumidores.

\section{Conclusões}

A análise dos dados coletados permitiu identificar a complexidade da questão da demanda de longa distância para destinos com severas limitações de acesso. Nos tempos atuais, com as facilidades de deslocamento cada vez mais evidentes entre os diversos cantos do globo terrestre, a inexistência de aeroportos com voos regulares nos destinos estudados é um fator chave para explicar a predominância de visitantes oriundos de núcleos emissores localizados em um curto raio de distância. Este aspecto foi evidenciado na presente pesquisa por meio do restrito número de pessoas que se enquadravam no universo de interesse, o qual era composto somente pela demanda originada em núcleos emissores distantes. Com esta constatação, questiona-se o caráter irradiador que estes destinos possuem, já que, ainda que tenham sido anteriormente classificados como indutores do turismo, suas demandas efetivas são compostas majoritariamente por consumidores de suas proximidades. Sendo o objetivo inicial da criação dos destinos indutores o de irradiar para sua região a demanda recebida, observa-se este como parcialmente comprometido, à medida que parte desta demanda, provavelmente, é da própria região.

Foi identificada uma pequena parcela de turistas que efetivamente viaja para conhecer e desfrutar dos grandes atrativos presentes nos destinos pesquisados, realizando deslocamentos de longa distância para visitar esses pontos especiais. Contudo, esse público é proporcionalmente tão pequeno que se perde na multidão dos turistas de curta distância, os quais fazem viagens com motivações menos específicas e, às vezes, quase cotidianas. Assim, mesmo que esses atrativos especiais tenham o poder de motivar alguns turistas de longa distância, o fluxo por eles gerado não é significativo em números absolutos e tampouco em relação ao fluxo receptivo total dos destinos.

Sobre a demanda que foi pesquisada, destaca-se que a maioria não estava visitando o destino pela primeira vez. Este aspecto evidencia uma relação diferenciada entre o turista e o destino, não sendo esta uma viagem de lazer tradicional em busca de se conhecer novos lugares. Em viagens deste tipo os destinos raramente são revisitados, já que há muitos outros lugares a serem conhecidos. Assim, nota-se um apego sentimental com os lugares visitados, o que pode vir a influenciar na composição de demanda e, consequentemente, na eventual estagnação do destino no longo prazo. Por outro lado, este apego pode levar o turista a divulgar e contribuir para a formação de uma imagem positiva do destino. Esse tipo de contribuição pode ser fundamental para o sucesso de mercado do destino nestes tempos em que a Internet e as redes sociais desempenham papéis cada vez mais relevantes no processo decisório de escolha dos destinos a serem visitados.

Apesar das grandes distâncias percorridas e de uma parcela significativa ter feito a maior parte da viagem por modal terrestre, as avaliações dos turistas sobre a dificuldade de acesso e a experiência global da viagem foram em geral positivas. A distância percorrida não se mostrou significativamente decisiva para a formação de opiniões negativas ou positivas sobre os meios de transporte utilizados ou sobre a qualidade das estradas. Sobre estes aspectos, formulam-se as seguintes hipóteses explicativas para as constatações obtidas: a) como grande parte dos turistas que já tinha visitado os destinos anteriormente, eles já esperavam encontrar as dificuldades de acesso existentes; b) as informações obtidas previamente deixaram os turistas preparados para as dificuldades de acesso existentes; e c) a demanda turística dos destinos pesquisados é composta por pessoas com perfil psicográfico mais propenso a vivenciar aventuras. Sugere-se que estas três hipóteses venham a ser tema de pesquisas futuras. 


\section{Bibliografia}

Araujo, C M. e Taschner, G.

2012. "Turismo e políticas públicas no Brasil." In Beni, M. C., Turismo: planejamento estratégico e capacidade de gestão (pp. 69-86). Barueri: Manole.

Barbosa, L.

2014. Índice de competitividade do turismo nacional: destinos indutores do desenvolvimento turístico regional: relatório Brasil 2014. Brasília: Ministério do Turismo, SEBRAE Nacional e Fundação Getúlio Vargas.

Beni, M. C.

2001. Análise estrutural do turismo. 5.ed. São Paulo: Senac.

Beni, M. C.

2006. Política e planejamento de Turismo no Brasil. São Paulo: Aleph.

Bezerra, D. M. F.

2003. "Programa Nacional de Municipalização do Turismo: análise de uma política pública em desenvolvimento". (pp. 48-67). In Bahl, Miguel. Turismo: enfoques teóricos e práticos. São Paulo: Roca.

Boullón, R. C.

2002. Planejamento do espaço turístico. Bauru: Edusc.

Brasil

1991. Lei 8181 de 28 de março de 1991: Dá nova denominação à Empresa Brasileira de Turismo

(Embratur), e dá outras providências. Brasília: Brasil.

Brasil, MTur.

2003. Plano Nacional do Turismo: diretrizes, metas e programas 2003/2007. Brasília: MTur.

Brasil, MTur.

2005. Plano Cores do Brasil: marketing turístico nacional. Fase I - diagnóstico. Brasília: MTur.

Brasil, MTur.

Plano Nacional de Turismo 2007/2010: uma viagem de inclusão. Brasília: MTur.

Brasil, MTur.

2013. Plano Nacional do Turismo: o turismo fazendo muito mais pelo Brasil 2013/2016. Brasília: MTur. Brasil, Mtur.

2015a. Categorização dos municípios das regiões turísticas do mapa do turismo Brasileiro: cartilha. Brasília: MTur.

Brasil, MTur.

2015b. Mapa de regionalização do turismo. Disponível em http://mapa.turismo.gov.br/mapa/\#/home. Acesso em 26/10/2015. Brasília: MTur.

Castells, M.

2001. "Internet e sociedade em rede". (pp.255-288). In: Moraes, D. (org.), Por uma Outra Comunicação: Mídia, Mundialização Cultural e Poder. Rio de Janeiro: Record.

Cruz, R. C. A.

2000. Política do turismo e território. São Paulo: Contexto, 2000.

Fratucci, A. C.

2005. "Participação comunitária na gestão do turismo nos municípios do Estado do Rio de Janeiro: análise do processo do PNMT". (pp. 1-22). In: Bartholo, R.; Delamaro, M.; Badin, L.. Turismo e sustentabilidade no Estado do Rio de Janeiro. Rio de Janeiro: Garamond.

Fundação Centro de Pesquisas Econômicas e Sociais do Piauí - CEPRO.

2013. Relatório de pesquisa: Demanda Turística, Litoral do Piauí. Teresina: CEPRO.

Guerra, A. C. e Gosling, M. e Coelho, M. de F.

2014. "Redes sociais: um jornal on-line como fonte de informação especializada em turismo". Revista Brasileira de Pesquisa em Turismo, 8 (3): 403-418.

Instituto Brasileiro de Geografia e Estatística - IBGE.

2010. Censo Populacional. Parnaíba-PI, 2010. Disponível em: http://www.ibge.gov.br Acesso em: 29. set.2015. Brasília: IBGE.

Instituto Brasileiro de Geografia e Estatística - IBGE.

2014. IBGE cidades@. Disponível em: http://www.cidades.ibge.gov.br/xtras/perfil.php?lang=\&codmun= 312160\&search=minas-gerais | diamantina. Acesso em: 8.jun. 2015. Brasília: IBGE. 
Instituto Brasileiro de Geografia e Estatística - IBGE.

2015. IBGE cidades@: Bahia-Lençóis. Disponível em: http://www.cidades.ibge.gov.br/xtras/perfil.php ?lang=\&codmun=291930\&search=bahia | lencois $\mid$ infograficos:-informacoes-completas. Acesso em: 13.out.2015. Brasília: IBGE, 2015.

Lima, G. M. C. e Maia, M. F.

2010. O Público por trás da fita na Vesperata. Trabalho de Conclusão de Curso (Bacharelado em Turismo). Universidade Federal dos Vales do Jequitinhonha e Mucuri. Diamantina: UFVJM.

Marques, D. A. D.

2009. Estrada Real: patrimônio cultural de Minas Gerais - um estudo de Diamantina e Serro. Brasília: UnB, Dissertação (Mestrado). Mestrado Profissional em Turismo, Centro de Excelência em Turismo da Universidade de Brasília. Brasília: UnB, 2009.

Mckercher, B. e Lew, A.

2003. "Distance decay and the impact of effective tourism exclusion zones on international travel flows". Journal of Travel Research, (42): 159-165.

Misi, A e Silva, M. D. G. D.

1996. Chapada Diamantina Oriental - Bahia. Geologia e Depósitos Minerais. Salvador: Secretaria da Indústria, Comércio e Mineração / Superintendência de Geologia e Recursos Minerais..

OMT.

2003. Turismo internacional: uma perspectiva global. 2.ed. Porto Alegre: Bookman.

Pedreira, A. J.

2013. "Serra do Sincorá, Chapada Diamantina, BA: beleza paisagística e paleopláceres de diamante". (p.187-194). In: Winge M. et al. (eds). Sítios geológicos e paleontológicos do Brasil volume III. Brasília: CPRM.

Pereira, B. T. da S. e Silva, L F.O. e Perinotto, A. R. C.

2011. "Festejo de São Francisco: análise sobre uma alternativa de desenvolvimento do Turismo Religioso em Parnaíba (Piauí, Brasil)". Turismo \& Sociedade, 4 (2): 363-380.

Perinotto, A. R. C.

2013. "Investigando a comunicação turística de Parnaíba/PI-Brasil: internet e redes sociais, descrição e análise". Revista de Investigación en turismo y desarrollo local, TURyDES, 6, (15): 1-24.

Portas, V G. e Fuensanta, J R. S.

2014. "Cloud computing, turismo y protección de datos". Revista de análisis turístico - AECIT,17: 61-68.

Prefeitura Municipal de Lençóis

2015. Economia. Disponível em: http://www.lencois.ba.gov.br/economia Acesso em: 13.out.2015. Lençóis: PML.

Rabahy, W. e Vassalo, M. e Monti, E.

2008. "Crescimento do turismo: análise de aspectos intervenientes e a importância da proximidade dos mercados". Revista Itinerarium, 1: 1-29.

Santos, G. E. O. e Kadota, D.

2012. Economia do turismo. São Paulo: Aleph.

Santos, G. E. O.e Ramos, V. e Rey-Maquieira, J.

2015. "Length of stay at multiple destinations of tourism trips in Brazil". Journal of Travel Research, 54(.6): $788-800$.

Silveira, C. E. e Medaglia, J. e Paixão, D. L. D.

2014. "Política Pública de Turismo no Brasil: evolução estrutural, alterações da lógica partidária e tendências recentes de apoio ao turismo massificado" (pp. 65-90). In: Pimentel, T. e Emmendoerfer, M. e Tomazzoni, E. Gestão Pública do Turismo no Brasil: teorias, metodologias e aplicações. Caxias do Sul: Educs. 